\title{
Testing two simple pesticide runoff models in Northern Australian agriculture
}

\author{
$\underline{\text { Anzooman } M^{\text {ac }}}$, Silburn DM ${ }^{\mathrm{b}}$,Waters $\mathbf{D}^{\mathrm{b}}$, Ian Craig ${ }^{\mathrm{a}}$ \\ ${ }^{a}$ Department of Engineering and Surveying, University of Southern Queensland, Queensland \\ Email:u1024449@umail.usq.edu.au \\ ${ }^{b}$ Department of Natural Resource and Mines, Queensland \\ ${ }^{c}$ Cotton Research and Development Corporation \\ Email:u1024449@umail.usq.edu.au/Monia.Anzooman@dnrm.qld.gov.au
}

\begin{abstract}
The Paddock to Reef Integrated Monitoring, Modelling and Reporting program (P2R) (Department of Premier and Cabinet, 2009) is investigating ways to improve agricultural management practices and the quality of water entering the Great Barrier Reef. One of the major risks to GBR water quality is pesticide runoff from agricultural industries. Direct measurement of pesticide fate and behavior is both cost and time intensive. Modelling therefore offers a logical way forward in assessment of improved management scenario to reduce pesticide runoff to the GBR. Modelling also confers the advantage that it can extrapolate from a relatively small experimental database, to a wider range of conditions and years.
\end{abstract}

The 'Simplified Formula for Indirect Loading caused by runoff' (SFIL) from The Organization for Economic Cooperation and Development (OECD) and the one-dimensional simulation model HowLeaky? are both paddock scale models used for the prediction of pesticide runoff. We tested the applicability of these models to predict paddock scale (edge-of-field) pesticide runoff against experimental data. The experimental data was from two North-East Australian sites with three kinds of cotton management, 'conventional', cotton grown in wheat stubble and Polyacrylamide (PAM) added to irrigation water. The simulations were carried out for the eight most frequently detected pesticides.

The SFIL-OECD modelled total pesticide loads in runoff were 1.4 to 2.8 times lower than measured loads for various pesticides. The HowLeaky? modelled total pesticide load was $5-23 \%$ higher than the measured load using parameter values from the literature. HowLeaky? was able to model similar trends in pesticide concentration compared to measured data following small adjustments to the most sensitive parameters. A sensitivity analysis indicated that the most significant model parameter for the SFIL model was pesticide soil half-life, while for the HowLeaky? model soil half-life, runoff curve number and application rate or efficiency were most significant.

The HowLeaky? model was then used to compare pesticide runoff estimates for 'old' (pre-genetically modified cotton) and 'new' pesticides. The rationale for this was that pesticide usage patterns changed significantly with the introduction of genetically modified cotton, particularly with replacement of soil residual herbicides by knockdown herbicides and insecticides with BT cotton. Therefore the pesticide runoff profile has changed accordingly. Comparing the old and new pesticide runoff profiles suggests that use of new pesticides will result in less pesticide runoff in the GBR.

This work demonstrates the value of models for predicting the environmental fate of pesticides and thus accessing the amount of pesticide entering streams. Future work will investigate the ecotoxicological implications of a shift in application patterns towards the 'new' pesticides.

Keywords: Insecticide, herbicide, cotton, simulation modelling, HowLeaky? 


\section{INTRODUCTION}

Sediments, nutrients and pesticides from the Great Barrier Reef (GBR) catchments in Queensland pose a threat to water quality in riverine environment and the reef lagoon. Over the past 150 years, GBR catchments have been modified for agricultural production and urban settlement. As a result the quality of water entering the GBR lagoon has declined (De'ath and Fabricius, 2010). In 2003, Reef water Quality Protection Plant (Reef Plan) was introduced and was reviewed in 2009 through a joint Queensland and Australian Government initiative (Department of Premier and Cabinet, 2009) which set a target of a 50\% reduction in the pesticides entering the Great Barrier Reef lagoon by 2013.

To measure the progress towards targets, a combined monitoring and modelling program at paddock through to catchment and reef scales has been established; The Paddock to Reef Program. Direct measurements of pesticides runoff from a paddock can be time and cost intensive and therefore sometimes not practical and effective for the assessment of pesticides runoff. Predictive models are a logical approach to extrapolate from the relatively small experimental database to a wider range of conditions and to investigate the impact of management options (Connolly et al., 1999, 2001; Shaw et al., 2011).

Waters et al., (2001) ran a three year project in Emerald, Queensland which aimed to develop management strategies that would minimize off-site movement of pollutants (sediment, nutrient, pesticides) at the paddock or farm scale. This study focused on total runoff, sediment, nutrient and pesticides runoff for all irrigation and rainfall events.

This paper describes the use of the simpler SFIL-OECD model and a water balance model, HowLeaky? to predict the load and concentrations of pesticide runoff from paddock areas. Both are reasonably simple simulation tools with easily accessible input data. Comparisons of predicted runoff and soil losses and pesticide concentrations and event loads were made with measured from the field studies of Waters et al., (2001).

\section{THE EMERALD STUDY SITE: EXPERIMENTAL DATA}

In 1997 after a series of industry and grower meetings, the project "Best Management Practices to Minimize Pollutant Transport from Cotton Production Systems" was developed. The aims were to develop practical and innovative management practices that would reduce off-site movement of soil, water, nutrient and pesticides. In particular, the goal was to apply small scale research findings "on farm" at the paddock scale to assess the practicality and feasibility of growers implementing the systems. The experiment was undertaken in Emerald, Queensland on two adjacent commercial farms.

Table 1. Emerald Site Study Detail

\begin{tabular}{|l|l|}
\hline Experiment Name & Treatment \\
\hline Experiment 1, Test 1 (E1T1) & Conventional Cotton \\
\hline Experiment 1, Test 2 (E1T2) & Wheat Stubble/ Cotton double crop \\
\hline Experiment 2, Test 1 (E2T1) & Conventional Cotton \\
\hline Experiment 2, Test 2 (E2T2) & Conventional Cotton with PAM \\
\hline
\end{tabular}

Three management practice treatments were trialled on the two farms (Table 1) with a total of four paddocks monitored overall. For experiment 1, there was a conventional cotton treatment (E1T1) and cotton planted into wheat stubble often referred to as wheatcotton double crop rotation (E1T2). For experiment 2, conventional cotton (E2T2) and for the second treatment polyacrylamide (PAM), a flocculent used to remove sediment bound pollutants, was added to irrigation water (E2T2). All four paddocks were approximately $27 \mathrm{Ha}$ in area. The experiments were conducted over two cotton growing seasons 1997/98 and 1998/99. Rainfall for 1997/98 was $386 \mathrm{~mm}$, which is in the driest $20 \%$ of years. In contrast, in the second year of the trial, double the rainfall of the first season was recorded $(767 \mathrm{~mm})$. The contrasting rainfall for the two seasons is reflected in the runoff and erosion results with double the erosion occurring in year two compared to year 1 (Waters, 2001). Runoff depth, sediment, nutrient and pesticide samples were collected for all irrigation and rainfall runoff events over the two seasons at the paddock outlets through constructed weirs. Pesticide were analyzed as total concentrations (sediment plus dissolved) in runoff.

In 1997/98 approximately $90 \%$ of runoff was from irrigation, due to the below average rainfall. For 1998/99, $63 \%$ of the runoff was from rainfall. The wheat-cotton treatment (E1T2) reduced soil loss by $70 \%$ over two seasons compared to conventional cotton (E1T1). For E2T2, PAM cotton reduced soil loss by $80 \%$ over two seasons compared to conventional cotton (E2T1). 


\section{MODEL OVERVIEW}

We reviewed existing runoff models eligible for modelling pesticides. Only models that simulate surface runoff and pesticide runoff were considered. SFIL-OECD model and HowLeaky? model have both been used for modelling in Australia and were selected.

SFIL-OECD model (Schriever et al., 2006) is a reasonably simple empirically derived model used for 'screening' purposes. It has been used for assessing the fate of pesticides for registration in Australian agriculture (APVMA, 2012) with minimal testing against experimental data. It is easy to implement in a spread sheet. SFIL-OECD model is based on simple equations where the paddock areas, application rate, half-life in soil, slope and sorption coefficient are considered. SFIL-OECD model has been used in Germany at broader scales for spatially explicit prediction of exposure (Brenzen et al., 2005).

HowLeaky? model has a long history of testing and application to environmental issues in Northern Australian Agriculture (e.g. Robinson et al., 2010; Shaw et al. 2011). HowLeaky? was selected because it was developed and validated for similar crop growing environments to those described in this paper. HowLeaky? is a one dimensional physically based model of hydrology, erosion and pesticide runoff at paddock scale. The model is suited to the simulations with modules available for managing furrow irrigation application and runoff and applying pesticides above or below canopy or to the soil or stubble. The model has been used in the GBR catchments already and further evaluation with measured data through this work is useful to increase confidence in model predictions.

\subsection{SFIL-OECD Pesticide model}

Formula (Eq. (1)) used for the simulation of the percentage of the pesticide application dose in runoff is

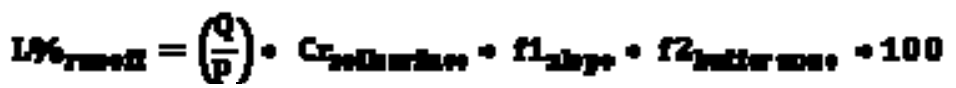

(Brenzen et al., 2005)

Where, $\mathbf{L} \mathbf{x}=$ percentage of application dose available in runoff water as dissolved substance, $\mathbf{P}=$ Daily precipitation (mm/day) and $\mathrm{Q}=$ Runoff Volume (mm/day) (Brenzen et al., 2005).

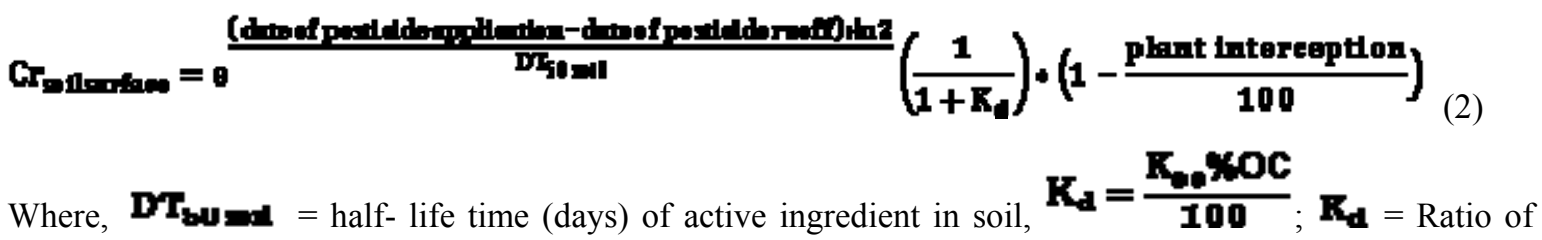
dissolved to sorbed pesticide concentrations, $\mathbf{K}_{\mathbf{0}}=$ sorption coefficient of active ingredient to organic carbon and $\mathrm{OC} \%=$ organic carbon content of soil.


of days after application. Only the contribution to the dissolved concentration in water is considered. Removing the $\mathrm{K}_{\mathrm{d}}$ term provides an estimate of the total concentration (sediment plus dissolved) in runoff. After application the compound is degraded using first order kinetics (Brenzen et al., 2005). For the herbicides the proportion of pesticides reaching the stubble/soil does not depend on plant interception whereas, for insecticides the proportion of pesticides that reaches the stubble/soil depends on the amount that is intercepted by the plant.

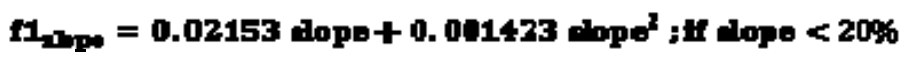

For slopes below $20 \%$ the loss of runoff increases according to the formula (f1 slope) and is constant (1.0) for slopes larger than 20\%. The buffer function (CFC, model also has equations for estimating the amount of runoff (based on empirical European hydrology). These were not used so that the estimation of pesticide runoff could be tested, without errors from runoff estimation. Rather, measured runoff amounts were used.

\subsection{HowLeaky? Pesticide model}

The HowLeaky? water balance and crop growth models are based on PERFECT (Littleboy et al., 1992) and have been described elsewhere (Robinson et al., 2010). Equations implemented in the pesticides module have 
been adapted from GLEAMS (Leonard et al., 1987) and have been described by Shaw et al., (2011). In HowLeaky? the total loss of pesticides in runoff is a function of pesticide application, degradation on and wash off from crop/stubble to soil, temperature dependent half-life, soil concentration after leaching and pest concentration in soluble and sorbed forms in runoff.

The four cropping sequences (Table 1) were simulated for the 2 years. Simulated runoff was calibrated by adjusting the runoff curve number and soil erosion by adjusting the erodibility. Water balance outputs included runoff from rainfall $(\mathrm{mm})$ and total amount of runoff (rainfall and irrigation). The soil output was the erosion ( $\mathrm{t} / \mathrm{ha}$ ) caused by runoff. Simulations were carried out for all pesticides listed in Table 2. Pesticide (active ingredient) outputs were the runoff concentration (ug/l) and total lost in runoff $(\mathrm{g} / \mathrm{ha})$.

\subsection{Model Parameters}

Both SFIL-OECD and HowLeaky? simulation models predict the amount of pesticide in runoff based on model parameters such as soil and crop parameters, pesticide properties.

The soil type at the experimental is a Black Vertosol. The Howleaky? model was parameterized with a 240 $\mathrm{mm}$ plant available water capacity of $1.5 \mathrm{~m}$ depth, was based on measurements undertaken at a nearby farm reported in Shaw and Yule (1978). Runoff curve number was set to 70 after calibration to measured rainfall runoff, comparable with 72-74 used by Connolly et al. (1999) on a nearby irrigated farm on the same soil type. Applied irrigation amounts and irrigation runoff volumes were supplied to the model as direct inputs to reduce possible sources of error given the focus of the work was on pesticide load prediction. Patterns for green and dead cover and rooting depth over time were based on field records.

The pesticide model in HowLeaky? and its parameters are described in Shaw et al., (2011). Pesticide parameters required for the models (Table 2) were selected from literature values. Application efficiency was $75 \%$ for all compounds, except pendimethalin (95\%), based on initial losses observed by Silburn (2003) at a nearby site. Though 22 pesticides were applied in the Emerald study from 1997-1999, load estimates derived from measured field data were available for only four herbicides and four insecticides (Table 2). Herbicides were all applied below the canopy and all insecticide applied above the canopy.

Table 2. Pesticide parameters used in the models from literature (and after calibration of HowLeaky?)

\begin{tabular}{|c|c|c|c|c|c|c|c|}
\hline $\begin{array}{c}\text { Active } \\
\text { Ingredient }\end{array}$ & \multicolumn{2}{|c|}{$\begin{array}{l}\text { Soil Half life } \\
\text { (days) }^{\mathrm{a}} \\
\text { Book values / } \\
\text { adjusted for } \\
\text { HowLeaky? }\end{array}$} & $\begin{array}{c}\text { Degradation } \\
\text { Activation } \\
\text { Energy }(\mathrm{J} / \mathrm{mil})^{\mathrm{b}}\end{array}$ & $\begin{array}{l}\text { Application rate } \\
\text { of active } \\
\text { ingredient } \\
\text { (g.a.i/ha) }\end{array}$ & $\begin{array}{c}\text { Number of } \\
\text { Applications } \\
\text { per year }\end{array}$ & $\begin{array}{c}\text { Sorption } \\
\text { Coefficient } \\
\mathrm{Kd}^{\mathrm{a}}\end{array}$ & $\begin{array}{l}\text { Cover Washoff } \\
\text { fraction }^{c}\end{array}$ \\
\hline Prometryn & 60 & 56 & 56100 & 500 & 1 & 6.4 & 0.5 \\
\hline Diuron & 90 & 70 & 32800 & 1500 & 1 & 480 & 0.45 \\
\hline Pendimethalin & 90 & 34 & 51800 & 950 & 1 & 80 & 0.24 \\
\hline Trifluralin & 60 & 55 & 52500 & 1349 & 1 & 128 & 0.4 \\
\hline$\alpha$-Endosulfan ${ }^{\mathrm{D}}$ & 50 & 45 & 100,000 & 1512 & $3-7$ & 78.9 & 0.5 \\
\hline$\beta$-Endosulfan & 150 & 110 & 100,000 & 648 & $3-7$ & 320 & 0.5 \\
\hline Chlorpyrifos & 20 & 20 & 65400 & 1755 & 1 & 6070 & 0.65 \\
\hline Parathion & 5 & 4 & 74510 & 1000 & 3 & 82 & 0.65 \\
\hline Profenofos & 8 & 6 & 65400 & 1875 & 3 & 32 & 0.9 \\
\hline
\end{tabular}

a ("THE PPDB, Pesticide Properties Database," 2010), vegetation half-life derived from the soil half-life using rules from SWAT. Reference temperature for half-life was $20^{\circ} \mathrm{c}$.

${ }^{\mathrm{b}}$ Degradation Activation Energy, values from Walker et al., (1997), EFSA (2007), or default of $65400 \mathrm{~J}^{\mathrm{mol}}{ }^{-1}$ if no compound specific estimates available.

${ }^{\mathrm{C}}$ SWAT pesticides properties database or estimated from relationship between solubility and available wash off coefficients.

D Endosulfan is composed of two isomers (alpha and beta) in the ratio 7:3.

\subsection{Sensitivity Analysis}

A sensitivity analysis was carried out on both models by changing the model parameters and observing the corresponding response on the selected simulation results. The model parameters were adjusted within the range of $+/-50 \%$ to perform a sensitivity check and those parameters which showed $40 \%$ or more change in model output were considered most sensitive to the model.

\subsection{Calibration for best fit}

To achieve the best fit in HowLeaky? initial parameters were entered based on literature and experimental data at the site. HowLeaky? showed over prediction in modelling pesticide concentration and total load in runoff, the model was re-calibrated to lower the predicted data (e.g. slightly shorter half-lives) and 
recalibrated by adjusting a number of the more sensitive pesticide parameters to get the best match with the observed data.

\subsection{Long-term Simulation Study Using HowLeaky?}

The introduction of genetically modified cotton to control insect pests and be tolerant of glyphosate caused a large change in the use patterns of insecticides and herbicides, according to industry survey data over many years (Pyke, 2007; Susan Maas, CRDC pers. comm.). For this simulation study we considered firstly the herbicides usage data for the older residual herbicides diuron, prometryn and trifluralin (Table 2), and their replacement for in-crop weed control, glyphosate (applied at $360 \mathrm{~g} / 1$ in 1 application a year). The older herbicides were frequently in use pre-1999. Then for insecticides, we considered the newer insecticides in use: Sumitomo Shield (active ingredient: clothianidin, applied at $200 \mathrm{~g} / 1$ in a maximum of 2-3 application per year) or dimethoate (applied at $3 \mathrm{l} / \mathrm{ha}$ in a maximum of 3 applications a year), replacing endosulfan. Application rate (from labels) and number of application per year (Pyke 2007) for older pesticides (Table 2) are often higher than newer products. We considered the same Emerald study site for this simulation, for conventional cotton only. Thus the same HowLeaky? soil and vegetation files for conventional cotton were used, with climate data for 1960 to 2012 for Emerald, QLD (62 yrs) which included years of high and low rainfall.

\section{RESULTS AND DISCUSSION}

\subsection{Sensitivity Analysis Results}

For both herbicide and insecticide SFIL-OECD model was sensitive to soil half-life and sorption coefficient. Land slope, runoff volume and application rate showed moderate sensitivity. Precipitation was the most sensitive parameter for both herbicides and insecticides. Plant interception is an important parameter for insecticides and was moderately sensitive to SFIL-OECD model outputs (data not shown).

In the HowLeaky? the soil half-life and application rate influenced the pesticide runoff concentration and total lost in runoff most, for both prometryn and alpha-endosulfan. The half-life of pesticides applied to vegetation had a minimal impact on model outputs. The runoff extraction coefficient had a moderate influence on both pesticide runoff concentration and total load. For example, a $50 \%$ change in runoff extraction coefficient resulted in less than $40 \%$ change in modelled load. The model was quite sensitive to soil bulk density with low sensitivity to runoff curve number.

\subsection{SFIL-OECD Pesticide Model Results}

In SFIL-OECD model, the predicted total pesticide loss $(\mathrm{g} / \mathrm{ha})$ in runoff (water and sediment) ranged from $6.23 \times 10^{-13}$ to $0.92 \times 10^{-2}$ for herbicides and $4.86 \times 10^{-7}$ to $0.82 \times 10^{-2}$ for insecticides without calibration. These are 1.4 to 2.8 times lower than the measured loads. When measured and modelled percentage of application dose available in runoff water as dissolved substance (L\% runoff) were compared, the SFIL-OECD model under-predicts the measured for both conventional and PAM cotton. The predicted total percentage of application dose in runoff ( $\mathrm{L} \%$ runoff) water for the dissolved substance ranged from $3.7 \times 10^{-5}$ to $4.61 \times 10^{-3}$ for herbicides and $1.5 \times 10^{-6}$ to $1.2 \times 10^{-3}$ for insecticides. Figure 1 shows the comparison between modelled and measured (A) total pesticide loss in runoff for trifluralin E1T1 and (B) runoff water in dissolved substances (L\% runoff) in E1T1 for conventional with the initial book values. All other herbicides and insecticides of E1T1, E1T2, E2T1 and E2T2 had similar results.

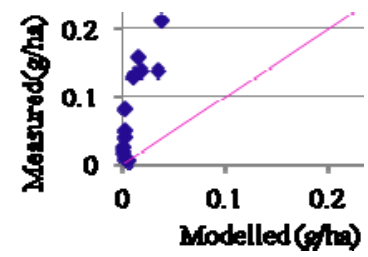

(A)

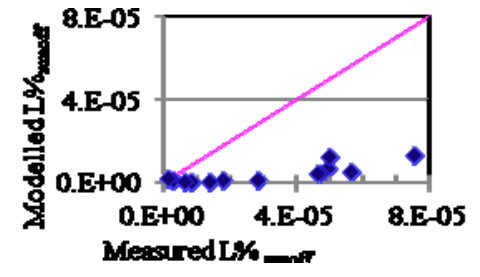

(B)

Figure 1. SFIL-OECD Modelled vs Measured (A) Total Pesticide loss (g/ha) and (B) L\% $\%_{\text {runoff }}$ for trifluralin. 


\subsection{Howleaky? Pesticide Model Results}

HowLeaky? model has been used to predict soil water balance (rainfall runoff), pesticide runoff concentration and total pest loss in runoff. There was good agreement between predicted and measured rainfall runoff for conventional cotton with the initial book values for pre-calibration (Figure 2) in particular for E1T1. HowLeaky? predictions were somewhat higher than observed runoff for E2T1 (conventional cotton). However, it was considered preferable to keep the runoff parameters the same for the two

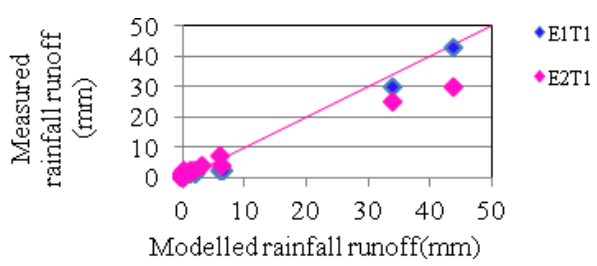

Figure 2. Modelled vs measured rainfall for two experiments (conventional cotton) sites.

Figure 3 and 4 present the comparison between predicted and measured pesticide concentrations for the herbicide prometryn for the conventional cotton treatment at Emerald. Other herbicides from the conventional cotton, wheat/double crop cotton and PAM cotton treatments followed the same pattern as presented for prometryn. Measured pesticide runoff concentrations (ug/l) for prometryn were lower than HowLeaky? predicted concentrations where literature derived parameters for pesticide soil half-life was used. Reduction of soil half-life by $25 \%$ and reduced application efficiency improved the match between measured and modelled concentrations $\left(\mathrm{R}^{2}=0.83\right.$ to $\left.\mathrm{R}^{2}=0.97\right)$. For other herbicides a similar pattern was found and calibration within 10\%-25\% reduction in soil half-life and 10\%-33\% reduction in application efficiency achieving the best fit of the data. These adjustments are consider small and reasonable considering that initial losses (e.g. volatilization) and more rapid half-lives have been measured for shallow surface soil (as in HowLeaky?) and in tropical environments than for deeper soil layers and temperate climates often used in literature studies (Silburn 2003).
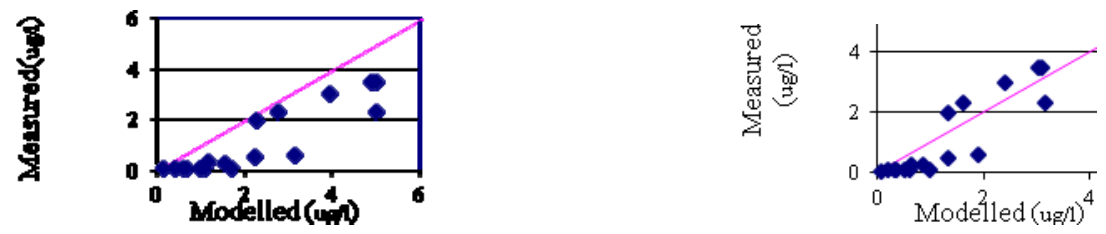

(A)

Figure 3. Modelled vs measured pesticide runoff concentration for prometryn-E1T1 (A) soil half life: 60 days, application efficiency: $75 \%$ and (B) soil half life: 45 days, application efficiency: 50\%



(A)

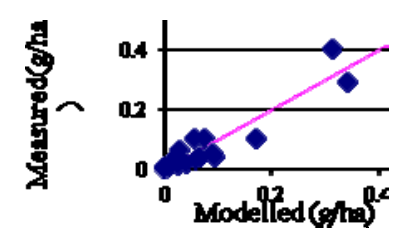

(B)

Figure 4. Modelled vs measured total pest lost in runoff for prometryn-E1T1 (A) soil half life: 60 days, application efficiency: $75 \%$ and (B) soil half life: 45 days, application efficiency: $50 \%$

\subsection{Long-term Simulation Study Result}

From the HowLeaky? long term simulations it was found that the use of newer insecticides like dimethoate and herbicides like glyphosate (pink line) can result in lower pesticide runoff concentrations and losses from paddock areas compared to the use of older pesticides (blue lines) (Figure 5). These responses are related to lower application rates and use, shorter half-lives and higher partitioning coefficients, all of which result in lower concentration in runoff. However, where new pesticides are being used, whilst they may result in lower application rates and lower amounts moving off farm, the off-site ecotoxicology effects

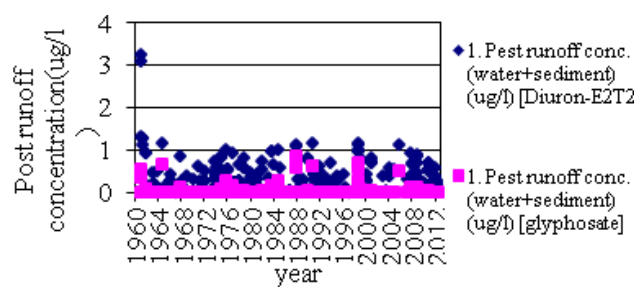

Figure 5. Predicted pesticide runoff concentration of diuron (older chemical) and glyphosate (new alternative) in ug/l 
must be considered for each compound.

\section{CONCLUSION}

The HowLeaky? pesticide model predicted runoff and soil erosion from rainfall reasonably well with book values of parameters and very well when calibrated against a site where extensive experiment data were available. Prediction of pesticide loss in runoff was slightly higher than measured, using default parameter vales, and some modification of parameter values was needed to adjust the model. However, insufficient data were available to perform an independent test. SFIL-OECD model provided much lower concentrations and total loads than were measured, indicating it needs more adjustment or that it may be too simplistic for local conditions. Predicted losses in runoff were most sensitive to the input soil half-life for both models, which highlights the importance of locally derived dissipation data for tropical regions and Australian soils (Shaw et al., 2011). Comparisons between cotton production systems using older residual herbicides and newer knockdown products indicates that this will lead to a reduction in herbicide losses off site. The alterative insecticide dimethoate has less toxicity than endosulfan, and the HowLeaky? simulations indicate a reduction in the total load of insecticide runoff from paddocks. Newer products have the advantage of being applied at lower rates which will lead to reduced runoff losses. Further investigation of the water quality implications of pesticide products which are being used more frequently is warranted. .

This study represents a somewhat simplistic investigation of older and newer pesticide regimes and testing using two simple pesticide models in use today. This work demonstrates the versatility of the Howleaky? model as a tool for predicting pesticide runoff from farming systems. Future work should test locally calibrated (or measured) parameter values against independent field data. Our future work will include the comparison calibrated parameters against local experimental datasets from another site.

\section{ACKNOWLEDGMENTS}

This research work is funded by Cotton R\&D Corporation (CRDC). The authors acknowledge the efforts of Dr. Melanie Shaw, DNRM, Dr. Bruce Pyke, CRDC and Prof. Ivan Kennedy, University of Sydney and the funding support from the Aust. and Qld governments under paddock to Reef Program.

\section{REFERENCES}

APVMA (2005). The Reconsideration of Approvals of the Active Constituent Diuron, Registrations of Products Containing Diuron and Their Associated Labels. Authority, Australian Pesticides \& Veterinary Medicines.

Brenzen,N., Lentzen-Godding, A., Probst, M., Schulz, H., Schulz,R., Liess, M., (2005)."A Comparison of Predicted and Measured Levels Of Runoff-Related Pesticide Concentrations in Small Lowland Streams on a Landscape Level". Chemophere 58: 683-91.

Connolly, R.D., Carroll, C., Frances, J., Silburn, D.M., Simpson, B., Freebairn, D.M. (1999). A simulation study of erosion in the Emerald Irrigation Area. Australian Journal of Soil Research 37, 479-494.

De'ath, G., Fabricius, K., (2010). Water quality as a regional driver of coral biodiversity and macroalgae on the Great Barrier Reef. Ecological Applications 20: 840-850.

Leonard, R.A., Knisel, W.G., and Still, D.A., (1987). GLEAMS: groundwater loading effects of agricultural management systems. Transactions of the ASAE 30, 1403-1418.

Littleboy, M., Silburn, D.M., Freebairn, D.M., Woodruff, D.R., Hammer, G.L., Leslie, J.K., (1992). The impact of soil erosion on sustainability of production in cropping systems. I. Development and validation of a simulation model. Australian Journal of Soil Research 30, 757-774.

Pyke, B.A., (2007). The Impact of High Adoption of Bollgard $\AA I I$ Cotton on Pest Management in Australia. World Cotton Research Conference - 4. Cotton: Nature's High-Tech Fiber, 10-14 Sept, 2007. http://wcrc.confex.com/wcrc/2007/techprogram/P1940.HTM

Robinson, J.B., Silburn,D.M., Rattary ,D., Freebairn, D.M., Biggs, A.J.W., McClymont, D and Christodoulou Modelling Shows That the High Rates of Deep Drainage in Parts of the Goondool Basin in Semi-Arid Queensland Can Be Reduced with Changes to the Farming Systems. ." Australian Journal of Soil Research 48 (2010): 58-68.

Shaw, M., Silburn, D.M., Thornton, C., Robinson, B., and McClymont, D. (2011). Modelling Pesticide Runoff Paddocks in the Great Barrier Reef Using Howleaky. In 19th International Congress on Modelling and Simulation Perth, Australia, 2011.

Schriever, C.,von der Ohe, P., Liess, M.,(2007). Estimating Pesticide Runoff in Small Streams.Chemosphere 68:2161-71.

Shaw, R.J. and Yule, D.F., (1978). The assessment of soils for irrigation, Emerald, Queensland. Agricultural Chemistry Branch, Technical Report No. 13. Queensland Department of Primary Industries.

Silburn, D.M. (2003). Characterising pesticide runoff from soil on cotton farms using a rainfall simulator. PhD. Thesis, University of Sydney

Waters, David. (2001). Best Management Practices to Minimise Pollutant Transport from Cotton Production Systems. In CRDC Final Report. NSW, Australia: Cotton Research and Development Corporation,.

Walker, A., Helwig, A, and Jacobsen, O.S,. (1997). Temperature and Pesticide Degradation. FOCUS 1. 